\title{
The Sda/GM2-glycan is a carbohydrate marker of porcine primordial germ cells and of a subpopulation of spermatogonia in cattle, pigs, horses and Ilama
}

 \\ ${ }^{1}$ School of Veterinary Medicine and Science and ${ }^{2}$ Division of Animal Sciences, School of Biosciences, University of \\ Nottingham, Loughborough LE12 5RD, UK, ${ }^{3}$ Anatomical Institute, University of Veterinary Medicine, Hannover, \\ Germany and ${ }^{4}$ Institute of Veterinary Anatomy, Justus-Liebig-University, Giessen, Germany \\ Correspondence should be addressed to K Klisch; Email: karl.klisch@nottingham.ac.uk
}

\begin{abstract}
Spermatogonia are a potential source of adult pluripotent stem cells and can be used for testis germ cell transplantation. Markers for the isolation of these cells are of great importance for biomedical applications. Primordial germ cells and prepubertal spermatogonia in many species can be identified by their binding of Dolichos biflorus agglutinin (DBA). This lectin binds to two different types of glycans, which are $\alpha$-linked $N$-acetylgalactosamine (GalNac) and $\beta$-linked GalNac, if this is part of the Sda or GM2 glycotopes. We used the MAB CT1, which is specific for the trisaccharides motif NeuAc $\alpha 2-3$ (GalNAcß1-4)Galß1-, which is common to both Sda and GM2 glycotopes, to further define the glycosylation of DBA binding germ cells. In porcine embryos, CT1 bound to migratory germ cells and gonocytes. CT1/DBA double staining showed that the mesonephros was CT1 negative but contained DBA-positive cells. Gonocytes in the female gonad became CT1 negative, while male gonocytes remained CT1 positive. In immunohistological double staining of cattle, pig, horse and Ilama testis, DBA and CT1 staining was generally colocalised in a subpopulation of spermatogonia. These spermatogonia were mainly single, sometimes paired or formed chains of up to four cells. Our data show that the Sda/GM2 glycotope is present in developing germ cells and spermatogonia in several species. Owing to the narrower specificity of the CT1 antibody, compared with DBA, the former is likely to be a useful tool for labelling and isolation of these cells.
\end{abstract}

Reproduction (2011) 142 667-674

\section{Introduction}

The search for new markers for spermatogonial stem cells has been fostered by the development of two new biotechnological applications for this cell type. First, the development of testis germ cell transplantation in rodents (Brinster \& Zimmermann 1994) and domestic livestock species offers new potentials for the generation of genetically modified offspring and also alternatives to artificial insemination (Hill \& Dobrinski 2006). Secondly, there is evidence that pluripotent stem cells can be derived from spermatogonial stem cells of rodents and humans without genetic transformation (Ko et al. 2009, Kossack et al. 2009). Such cells would be an alternative to embryonic stem cells (Dym et al. 2009).

In many species, primordial germ cells (PGCs) and spermatogonia show a very specific surface glycosylation pattern, which differs from that of the surrounding cell populations. The biological significance of this glycosylation pattern is still largely unknown, but it seems likely that the glycans play a role in cell migration and adhesion. Lectins and carbohydrate-specific antibodies are used to identify the specific glycosylation pattern of these cells. These reagents can be used to monitor cell purification procedures or for positive cell sorting (Herrid et al. 2009). A widely used marker for early stages in germ cell development in domestic mammals is the plant lectin Dolichos biflorus agglutinin (DBA), which binds to terminal $\mathrm{N}$-acetylgalactosamine (GalNAc) residues (Piller et al. 1990). DBA is often regarded as specific for $\alpha$-GalNAc, although it has been shown to bind to $\beta$-GalNAc, if this is part of the Sda (NeuAc $\alpha 2-3$ (GalNAc $\beta 1-4)$ Gal $\beta 1-4 G$ lcNAc-R) or GM2 NeuAc $\alpha 2-3$ (GalNAc $\beta 1-4)$ Gal $\beta 1-4 G l u-R)$ glycotopes (Piller et al. 1990, Wu et al. 1998, Klisch et al. 2008).

Several studies showed that the binding profile of DBA to germ cells changes during development. In cattle, DBA binds to prespermatogonia in early postnatal stages and also to the Golgi region in some basal spermatogonia in postpubertal bulls (Ertl \& Wrobel 1992). In the pig, DBA binds to PGCs and gonocytes, but to very few spermatogonia in the adult testis (Goel et al. 2007). Binding of DBA to bovine and porcine migratory PGCs has been demonstrated by Wrobel \& Suss (1998) and 
Takagi et al. (1997) respectively. DBA has been used to label spermatogonia in cattle (Izadyar et al. 2002, Herrid et al. 2007, Aponte et al. 2008, Fujihara et al. 2011), pigs (Takagi et al. 1997, Kim et al. 2010) and horses (Verini-Supplizi et al. 2000, Ha et al. 2003). It has also been used for the isolation of spermatogonia from bovine testis (Herrid et al. 2009, Anglin et al. 2010).

The use of DBA as a marker for isolating germ cells has the disadvantage that it also binds other cell types in neighbouring areas such as the mesonephros, as shown in the pig (Takagi et al. 1997). This lack of specificity restricts the application of this lectin for labelling cells prior to sorting by fluorescence-activated cell sorting (FACS) or magnetic beads.

In this study, we use a monoclonal mouse antibody CT1, which binds to the Sda/GM2 glycotope, to elucidate the configuration of GalNAc residues in spermatogonia of cattle, pigs, horses and Ilama, as well as porcine migratory PGCs and gonocytes.

\section{Results}

\section{CT1 binds only to the Sda and GM2 glycotopes}

On the Consortium of Functional Glycomics (CFG) glycan array, the CT1 antibody bound to three structures with very high specificity (Fig. 1). These were the Sda glycotope (Neu5Ac $\alpha 2-3$ (GalNAc $\beta 1-4)$ Gal $\beta 1-$ $4 \mathrm{Gl} C N A c \beta-$ ), which is present on the array twice (linked with two different spacers) and to the GM2 glycotope (Neu5Ac $\alpha 2-3$ (GalNAc $\beta 1-4)$ Gal $\beta 1-4 \mathrm{Glc} \beta$-; data are available on the CFG website: http://www.functionalglycomics.org/). A schematic drawing of these carbohydrate structures is given in Fig. 2. The binding specificity of DBA has been determined on an earlier

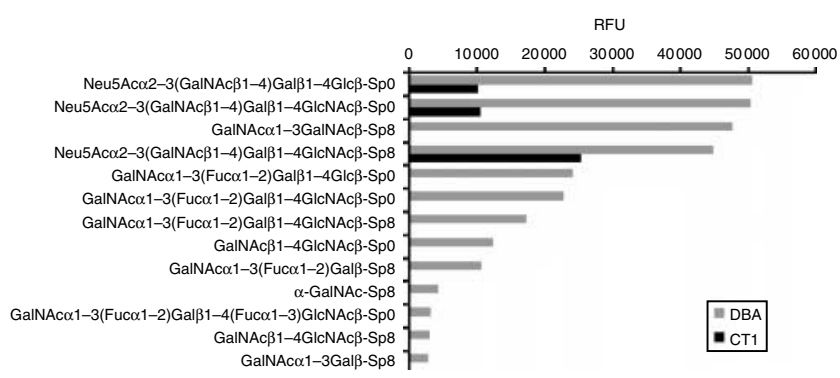

Figure 1 Binding data of $\mathrm{CT} 1$ and DBA to Consortium of Functional Glycomics (CFG) glycan arrays. The 13 carbohydrate structures with the strongest binding are shown. Complete data are available on the CFG website (http://www.functionalglycomics.org/). RFU, relative fluorescence unit. CT1 strongly binds to only two different glycans antibody, which are the Sda glycotope Neu5Ac $\alpha 2-3$ (GalNAc $\beta 1-4)$ Gal $\beta 1-4 G l c N A c \beta$ - (linked to the array by two different spacers (Sp0 and Sp8)) and the GM2 glycotope (Neu5Ac $\alpha 2-3$ (GalNAc $\beta 1-4)$ Gal $\beta 1-4 G l_{c} \beta-$-). All other, glycans show affinities that are about three orders of magnitude lower. DBA also binds strongly to the two glycans, which are recognised by $\mathrm{CT} 1$, but shows additional binding to several structures that mainly contain terminal $\alpha 1-3$ GalNAc.

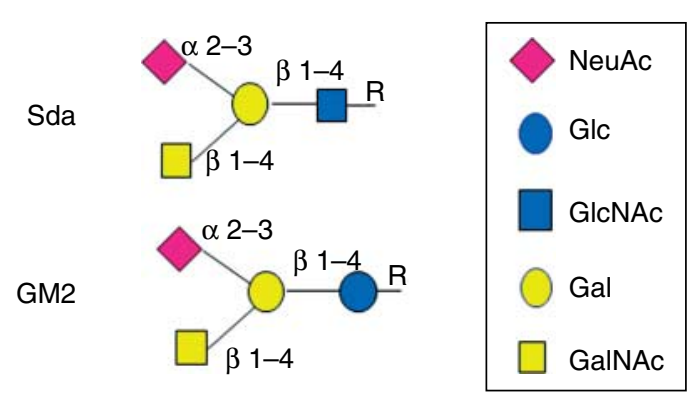

Figure 2 The Sda and GM2 glycotopes are branched carbohydrates, which have a terminal structure in common, which consists of sialic acid (NeuAc), N-acetylgalactosamine (GalNAc) and galactose (Gal). In the Sda glycotope, R stands for underlying carbohydrate chain, and in the GM2 ganglioside, $R$ is a ceramide.

version of the CFG glycan array. These data show that DBA binds to the Sda and GM2 glycotopes, but also to other structures, which mainly contain terminal $\alpha 1-3-$ linked GalNAc (Fig. 1).

\section{CT1 is expressed in early migratory pig PGCs}

We determined whether CT1 was expressed in early migratory pig PGCs. A clear CT1 signal was detected in cells located in the hindgut of E15 embryos (Fig. 3). These CT1-positive cells can be clearly distinguished from their somatic neighbours because they are large and show prominent round nuclei, which are typical features of PGCs. The CT1 cells also stained positive for DBA lectin (Fig. 3A). No other embryonic cells, except epidermal cells (Fig. 3A) and some rare gut epithelial cells, were stained with this antibody. The CT1-positive cells were also co-immunostained with POU5F1 (also known as OCT-4; Fig. 3B), which identifies migratory PGC at this stage of development (Hyldig et al. 2011).

\section{CT1 is expressed in gonocytes colonising the fetal gonad}

Then, we investigated the expression of CT1 binding sites during the development of the fetal gonad in the pig. CT1 staining was detected in late migratory PGC reaching the gonadal primordium of E22 embryos (Fig. 4). These cells also showed weak DBA staining. Later, by E28, PGCs colonising the gonads were abundant, and colocalisation of CT1 and DBA staining was detected in almost all PGCs, although some DBApositive cells were CT1 negative (Fig. 4, E28). The mesonephros of these embryos showed no CT1 immunoreactivity; however, many cells were stained with DBA. In the gonads of E28, E32, E42 and E51 embryos, CT1 and DBA were colocalised, although a small proportion of DBA +/CT1 - cells were always detected.

In ovaries from E75 embryos, CT1- and DBA-stained groups of gonocytes located in close proximity. Ovaries containing small primordial follicles showed a reduction 
A
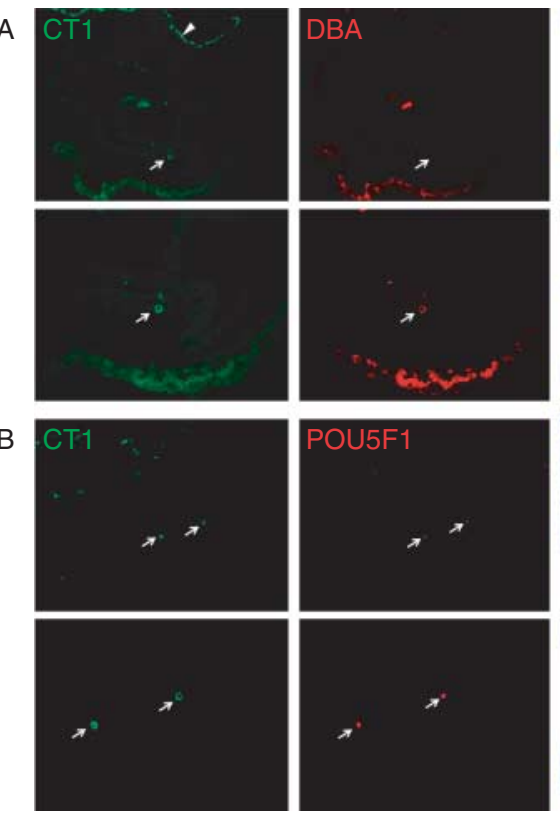
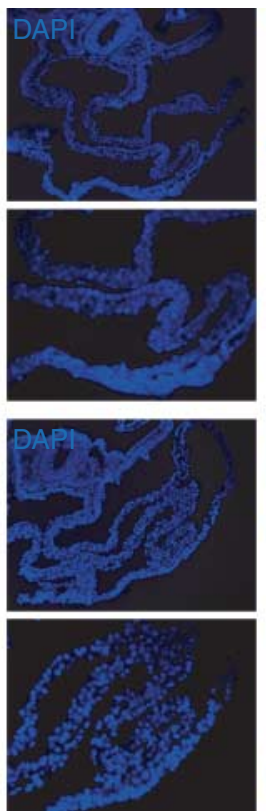
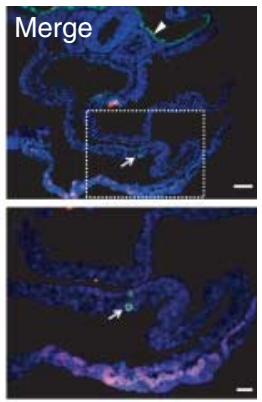

Merge
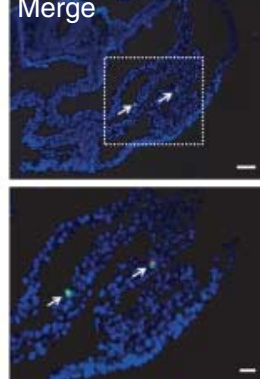

Figure 3 CT1 marks early migratory pig PGCs. Sections of E15 embryos co-stained with CT1 antibody (green), and either DBA (red) and antiPOU5F1 antibody (red). DAPI (blue) was used as counterstaining. The lower row of images for each panel shows a closer view demarcated by the square in the merge images. (A) Arrows point to the PGCs in the hindgut, which are CT1 and DBA positive. The epidermis is CT1 positive (arrowhead) but shows only weak DBA staining. Some

CT1/DBA staining was also detected in the extraembryonic membranes localised at the bottom of the picture. (B) The CT1-positive cells (arrows) in the hindgut are also POU5F1 positive. The higher magnification shows that the CT1 label is mainly cytoplasmic, while POU5F1 is located in the nuclei. Scale bar: $50 \mu \mathrm{m}$ for lower magnification and $20 \mu \mathrm{m}$ for higher magnification images. in CT1 but maintained DBA staining. In the testis of E75 embryos, bright CT1 and DBA staining was detected in gonocytes located in the testicular cords.

To confirm that CT1-positive cells were PGCs/gonocytes, we performed double immunostaining with POU5F1 and UCHL1 (Fig. 5). Sections of E32 embryos show clear nuclear POU5F1 staining and CT1 in the cytoplasm and membrane of PGCs. CT1 and UCHL1 staining was colocalised in E70 gonocytes.

\section{CT1 identifies a subpopulation of spermatogonia in postpubertal testes}

In postpubertal testis of cattle, pig, Ilama and horse, the CT1 antibody binds to a subpopulation of cells located at the basal membrane of the seminiferous tubules (Figs 6 and 7). The frequency of these cells was relatively high in cattle and lower in the llama and horse. In the sections of postpubertal pig testis, only very few CT1 immunoreactive cells were detected. In cattle and horse, the CT1 binding was mainly restricted to the perinuclear region of the cells, but membrane binding was also visible. The pig and llama showed a more diffuse cytoplasmic staining and also labelling of the cell membrane. The CT1-positive cells were generally single cells, but also pairs (see llama in Fig. 6) or 'chains' of up to four cells could be observed (not shown). This occurrence of such groups of CT1-immunopositive cells was most obvious in the Ilama specimens. In the llama, some cells, which were more apically located, showed immunostaining of a dense structure adjacent to the cell nucleus (data not shown).

To further elucidate the identity of the CT1-positive cells, we used a marker for spermatogonia (UCHL1, previously known as PGP9.5) in double staining with CT1 (Fig. 6). The UCHL1 antibody labelled spermatogonia in cattle, pig and Ilama, but not in horses. In cattle, the CT1 and UCHL1 staining was generally colocalised. In pig and Ilama, only a small fraction of the UCHL1positive cells were also CT1 positive (Fig. 6). In prepubertal porcine testis, CT1-positive cells were more frequent than in postpubertal testis. They were located either at the periphery of the seminiferous tubules (Fig. 6) or centrally (Fig. 7).

The CT1/DBA double staining (Fig. 7) revealed that CT1-positive cells in the seminiferous tubules were also DBA positive. DBA bound also to other CT1-negative cells. In cattle, there was DBA staining of spermatids. In sections of prepubertal pig testis, many cells inside the tubules were DBA positive, but CT1 negative. In horse and Ilama, CT1 and DBA labelled the same population of cells.

In controls, the omission of the primary reagent (DBA/CT1/anti-UCHL1) generally reduced the staining to a diffuse background, without any prominent labelling of a specific structure or cell type (see Supplementary Figures 1 and 2, see section on supplementary data given at the end of this article). One exception was the pre- and postpubertal pig testis, which showed a strong green signal in intertubular regions (probably Leydig cells) in the control sections.

\section{Discussion}

The lectin DBA binds to glycoepitopes with terminal $\alpha$-linked GalNAc (e.g. blood group A, Forssman and Tn antigens; Piller et al. 1990) and is therefore often regarded as specific for GalNAc in $\alpha$-linkage. But it also 


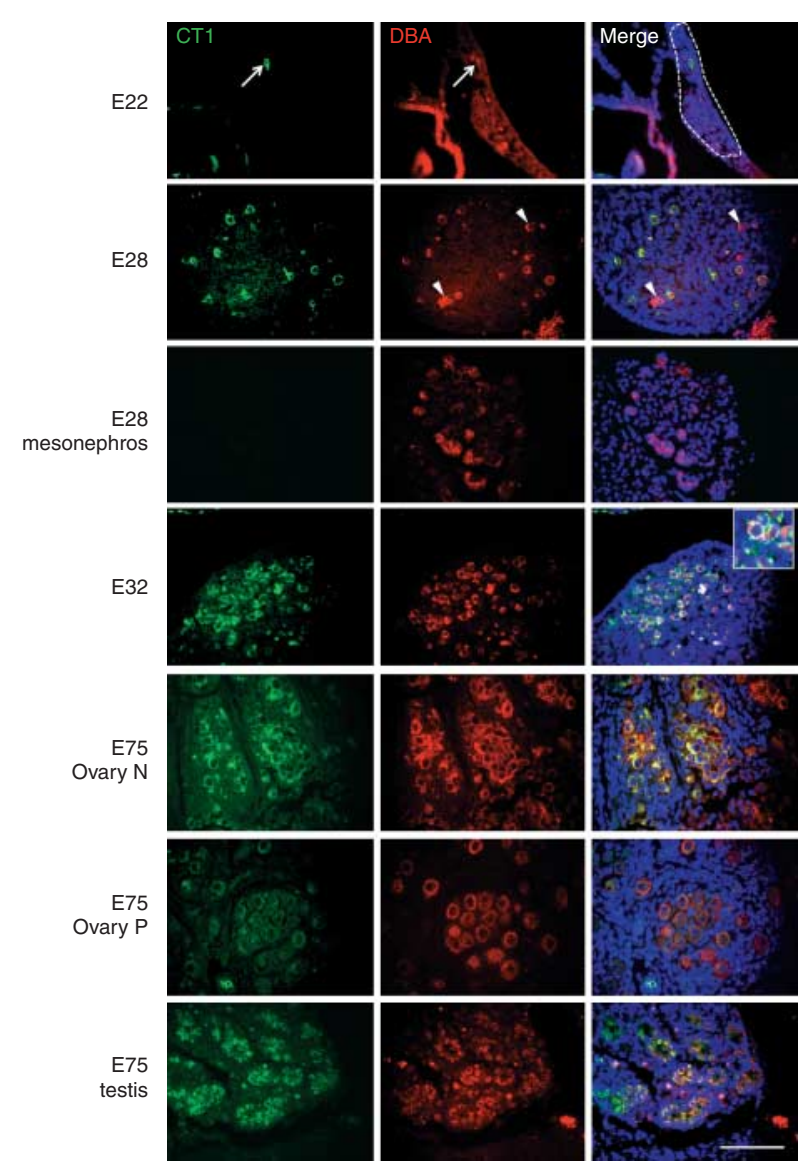

Figure 4 CT1 marks gonadal pig PGCs. Sections of embryos between E22-E75 stained with CT1 antibody (green) and DBA lectin (red). Arrows point to a migratory PGC reaching the gonadal primordium (dashed area) in an E22 embryo. CT1 staining was detected in individual gonadal PGCs (E28-E32), but did not mark cells in the E28 mesonephros, as is typical for DBA. A few DBA-positive cells (arrowheads in E28) were CT1 negative. The inset in E32 shows the colocalisation of DBA/CT1 in higher magnification. In later stages (E75), testicular cords and ovarian nests $(\mathrm{E} 75 \mathrm{~N})$ showed prominent CT1/DBA staining; however, some areas of E75 ovaries with primordial follicles (E75P) showed a marked reduction in CT1. Scale bar: $100 \mu \mathrm{m}$.

shows high affinity to $\beta$-linked GalNAc, if it is part of the Sda (GalNAc $\beta 1-4(N e u A c \alpha 2-3)$ Gal $\beta 1-4 G l c N A c-R)$ or the GM2 (GalNAc $\beta 1-4($ NeuAc $\alpha 2-3)$ Gal $\beta 1-4$ Glc-R) glycotopes (see Figs 1 and 2; Kamada et al. 1991, Klisch et al. 2008). Sda and GM2 glycotopes share the common terminal trisaccharide (GalNAc $\beta 1-4(\mathrm{NeuAc} \alpha 2-3)$ Gal $\beta 1-)$, but differ only in the underlying sugar, which is GlcNAc in Sda and Glc in GM2. The binding of DBA to $\alpha$-GalNAc as well as $\beta$-GalNAc is possibly due to an unusual configuration into which the $\beta$-GalNAc is forced by the adjacent $\alpha 2-3$-linked NeuAc (Harris \& Thornton 1978, Piller et al. 1990). The CT1 antibody shows a narrower binding specificity, since it only recognises the Sda and GM2 glycotopes.

Our results of the DBA staining in pigs and cattle are consistent with most previously published data. In our study, we found very few DBA-positive cells in porcine testis, which is in agreement with Goel et al. (2007), who also found a small number of DBA-positive cells in testis of a 5-month-old pig. Pinart et al. (2001) reported no DBA affinity to cells of the seminiferous epithelium in 9-month-old postpubertal porcine testes, indicating that in older boars the epitope bound by DBA is no longer present in spermatogonia. Very few cells bound DBA in the horse testis (Ha et al. 2003). Verini-Supplizi et al. (2000) found no DBA-positive cells in the postpubertal equine testis, but a strong reaction with degenerating spermatogonia in the prepubertal testis. Ertl \& Wrobel (1992) described DBA binding to the Golgi complex of bovine prespermatogonia and spermatogonia. Weak binding of DBA to bovine spermatogonia, acrosomes of spermatids and Leydig cells in the postpubertal tissue was described by Abd-Elmaksoud (2005).

Combined UCHL1 (PGP9.5) and DBA immunostainings were done in cattle (Herrid et al. 2007) and pig testis (Goel et al. 2007). Results of both studies are consistent with our findings. In pre- and postpubertal cattle, UCHL1 and DBA stain the same cells (Herrid et al. 2007). In pigs, the frequency of DBA-positive cells rapidly decreases after parturition, while UCHL1 staining remains constant (Goel et al. 2007). Our findings show that in the llama and in the pig, only a small proportion of the UCHL1-positive spermatogonia is CT1 positive. Since CT1 marks PGCs and gonocytes in earlier stages of development, the spermatogonia, which remain CT1 positive in the postpubertal testis, might be relatively undifferentiated. Whether this is linked to potential stem cell properties of these CT1-positive cells will need further elucidation.

The colocalisation of DBA and CT1 staining in the tissues studied suggests that the Sda glycotope is present in migrating porcine PGCs and a subpopulation of spermatogonia. Since GM2 ganglioside, which is also recognised by CT1, is a glycosphingolipid, the use of organic solvents during the histological preparation of our specimen should have removed this structure (Debarbieux et al. 2009). We would expect that only the Sda antigen, as part of glycoproteins, is responsible for the CT1 and DBA binding. The Sda glycotope is formed by the addition of GalNAc in a $\beta 1-4$ linkage to terminal 3'-sialyllactosamine residues. This final step of the synthesis is catalysed by the $\beta-4-N$-acetylgalactosaminyltransferase-2. The Sda glycotope has only been demonstrated in a limited number of glycoproteins. It was detected on $\mathrm{N}$-glycans in bovine pregnancyassociated glycoprotein (Klisch et al. 2008) and on Tamm-Horsfall protein (Easton et al. 2000a). The Sda antigen was also found on human and mouse zona pellucida protein-3 (Easton et al. 2000b) and on murine CD45 in activated cytotoxic T-cells (LeFrancois \& Bevan 1985). The functions of the Sda glycotope still remain unknown. It might be involved in the regulation of the half-life of glycoproteins in plasma (Klisch et al. 2008) 

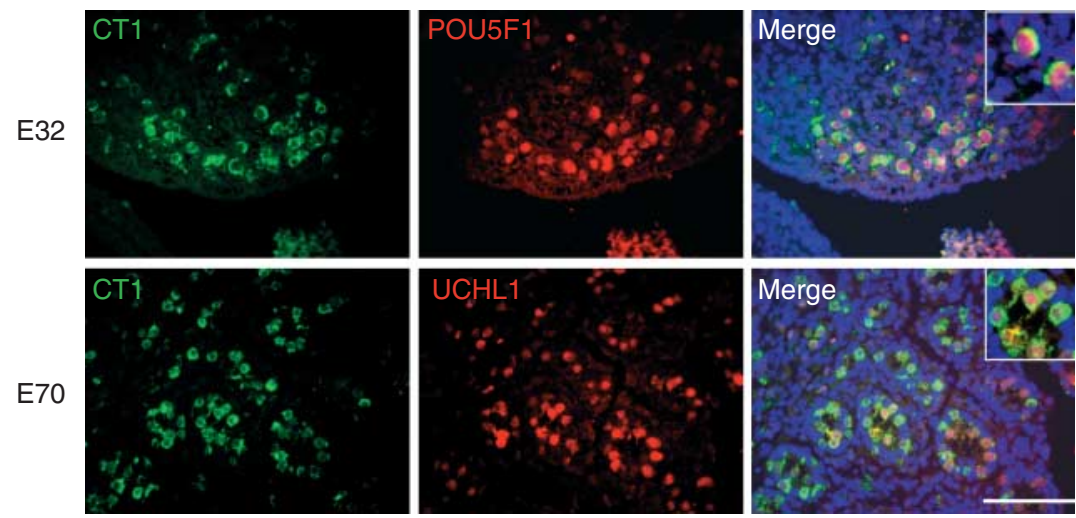

Figure 5 Anti-POU5F1 and anti-UCHL1 antibodies (red) were used to identify spermatogonial cells. The insets in both merged images show the colocalisation of these markers with CT1 (green) in gonocytes of E32 and E70 stages. Scale bar: $100 \mu \mathrm{m}$. and is possibly involved in protecting the human urinary tract from pathogenic Escherichia coli (Serafini-Cessi et al. 2005).

Surface markers are ideally suited for labelling germ cells prior to sorting using FACS or magnetic beads, and DBA has frequently been used for these purposes. DBA, however, binds to carbohydrates that are present in multiple cell types; thus, efficient sorting of cells based on the binding properties of this molecule depends on the location of the germ cells. For instance, in testis samples, DBA has been used for isolating type A spermatogonia using FACS (Izadyar et al. 2002) and magnetic separation (Herrid et al. 2009). For isolating PGCs from migratory stages, however, the use of DBA
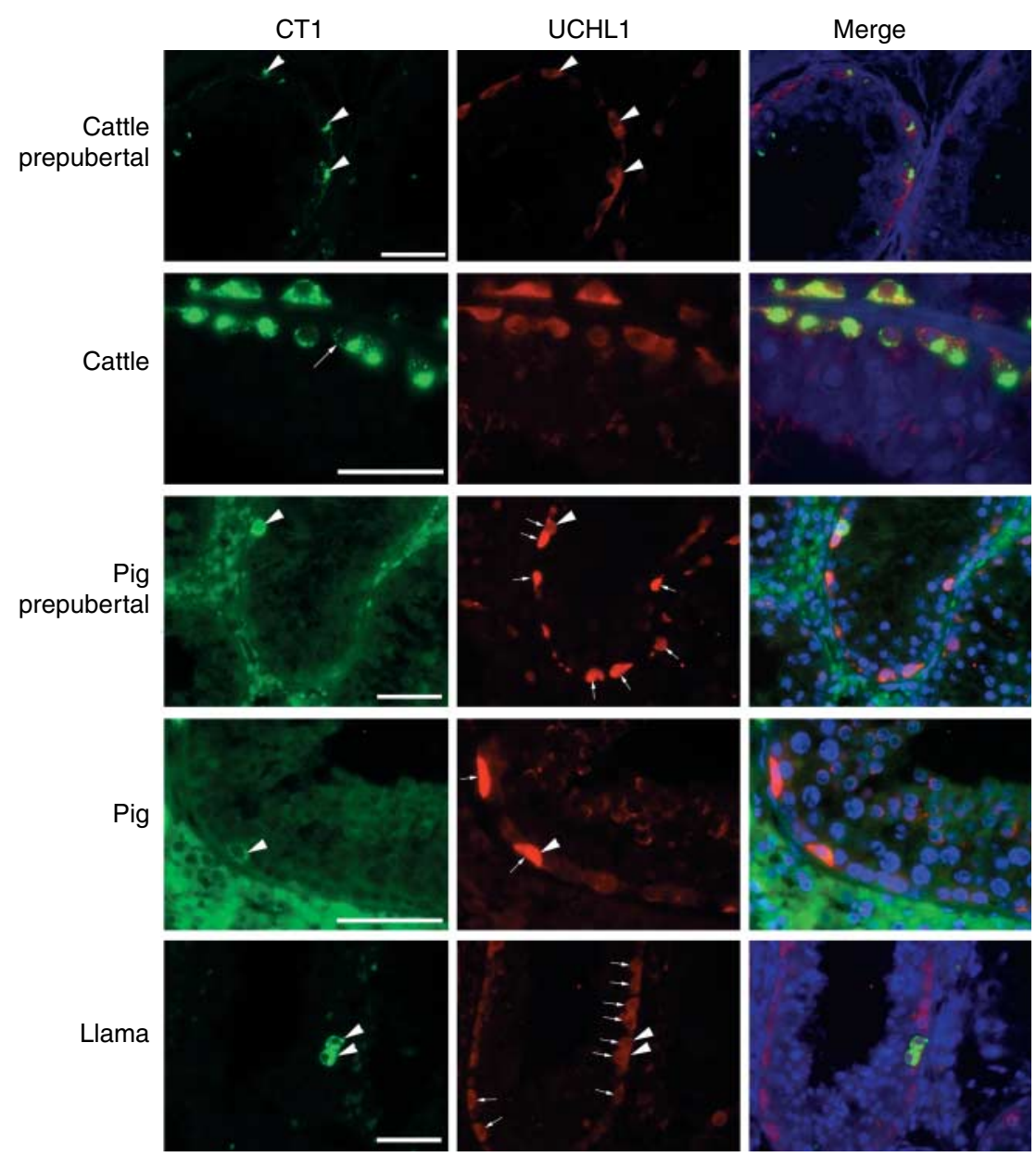

Figure $6 \mathrm{CT} 1$ and $\mathrm{UCHL} 1$ staining in postnatal testis. CT1 (green) and UCHL1 (red) double immunostaining of cattle (pre- and postpubertal), pig and Ilama testis. In prepubertal cattle, CT1 staining is found in all UCHL1-positive spermatogonia. The CT1 label is concentrated mainly in the perinuclear region (arrowheads) of the cells. The postpubertal cattle shows a similar pattern. At a higher magnification, the membrane staining with CT1 is clearly visible (arrow). In prepubertal pig testis, only a small proportion of UCHL1labelled cells were CT1 positive. These were located either in the periphery of the tubules (arrowhead) or centrally. In the postpubertal pig testis, CT1-positive cells were very rare (arrowhead) and were a subpopulation of the UCHL1positive cells (arrows). The strong green staining of intertubular cells in the pig specimens was unspecific, since it was also present in controls, in which the primary antibody (CT1) was omitted. In Ilama, CT1-positive cells were often seen in pairs (arrowheads), but single CT1-positive cells or chains of four cells were also present (not shown). The CT1 cells were a subpopulation of the UCHL1-positive cells (arrows). Scale bars: $50 \mu \mathrm{m}$. 


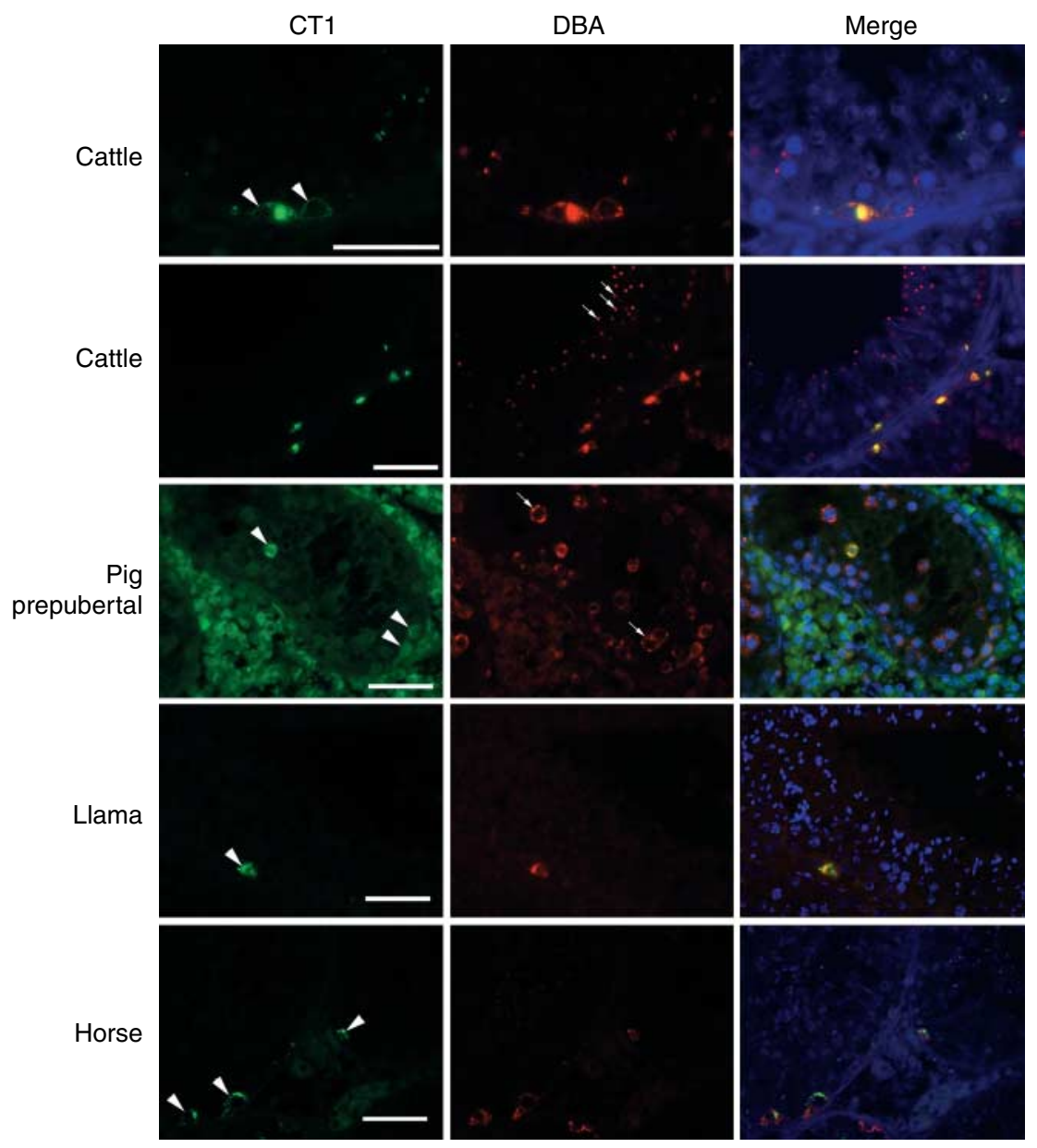

Figure 7 CT1 and DBA staining in postnatal testis. CT1 (green) and DBA (red) double immunostaining of postpubertal cattle, prepubertal pig, Ilama and horse testis. CT1-positive cells are highlighted by arrowheads. In cattle testis, CT1 and DBA are colocalised in spermatogonia. The staining is mainly in the perinuclear region of the cells, but also at the cell membrane. In cattle, some cells, which are located more apically in the seminiferous epithelium, show a dense perinuclear DBA staining (arrows). In the porcine prepubertal testis, only a few intratubular cells are CT1 positive (arrowheads), while many more are DBA positive (arrows). In Ilama and horse testis, CT1 and DBA staining is localised in cells (arrowheads) located basally in the seminiferous tubules. Scale bars: $50 \mu \mathrm{m}$. may be more problematic because cells in the mesonephros, a neighbouring structure to the migratory path of PGCs and to the gonadal ridges, also bind this molecule (our study; Takagi et al. (1997)). Our results with CT1 show that this antibody specifically marks PGCs in their migratory path and cells in the mesonephros are not labelled, making this antibody potentially suitable for cell-sorting applications. The strong background produced by the secondary antibody in our study could be overcome using a direct labelling approach for the CT1 antibody prior to FACS sorting. Further experiments with the CT1 antibody will be necessary to show whether this antibody is superior to the DBA lectin for the isolation of PGCs and spermatogonia in domestic animals.

In conclusion, this study established that Sda/GM2 epitopes are present on germ cells during early stages of development and become restricted to a small population of cells in the postpubertal male gonad. The identity of these rare cells in the postpubertal gonad is currently unknown, and future studies using CT1 antibody will determine whether these spermatogonia represent a unique population of germ cell progenitors.

\section{Materials and Methods}

\section{Materials}

All the procedures involving animals have been approved by the School of Biosciences Ethics Review Committee (University of Nottingham, UK). Porcine embryos were collected from artificially inseminated British Landrace sows or Yorkshire $\mathrm{X}$ Landrace gilts. Embryos were recovered from the pregnant uteri within between $30 \mathrm{~min}$ and $2 \mathrm{~h}$ of slaughter. Embryos of each of the ages $(15,22,28,32,42,51,70$ and 75 days) were fixed in $4 \%$ paraformaldehyde in PBS overnight at $4{ }^{\circ} \mathrm{C}$. Tissue was hereafter dehydrated through increasing ethanol concentrations to xylene and embedded in paraffin. Transversal sections of $5 \mu \mathrm{m}$ thickness containing the PGC were collected on SuperFrost Plus microscope slides (Menzel, Braunschweig, Germany).

Testicular tissue of cattle $(n=2)$, pigs $(n=3)$, horses $(n=2)$ and Ilamas $(n=2)$ was fixed in Bouin's fixative for $24 \mathrm{~h}$ and embedded in paraffin. The porcine and bovine testes were collected at a commercial abattoir. Llama and horse testes were obtained from castrations. Except for the llamas, which were aged 2-10 years, no information about the age of the animals was available. The testes of two animals (one cattle and one pig) were classified as prepubertal due to the absence of spermatozoa in the seminiferous ducts. 
The CT1-hybridoma was a gift from Leo Lefrancois, University of Connecticut, Farmington, CT, USA. The hybridoma cells were grown in medium (DMEM Ham's F12, 10\% FCS, $2 \mathrm{mM}$ L-glutamine, $1 \times$ penicillin/streptomycin and $1 \mathrm{mM}$ sodium pyruvate) until the cells died. The cells were removed by centrifugation and the supernatant was concentrated $\sim 20$ fold by ultrafiltration. The antibody concentration was estimated by dot-blot in comparison to an $\lg M$ solution of known concentration.

\section{Determination of $\mathrm{CT1}$ binding specificity}

An aliquot of the CT1 antibody $(0.1 \mathrm{mg} \lg \mathrm{M}$, freeze dried in culture medium) was sent to the protein-carbohydrate interaction core $(\mathrm{H})$ of the CFG for determination of its carbohydrate binding specificity. The antibody $(10 \mu \mathrm{g} / \mathrm{ml})$ was incubated on the version 4.1 of the printed Glycan Array, which consists of 465 glycans in replicates of six. Concentrated culture medium without antibodies was used as negative control.

\section{Immunohistochemistry}

Paraffin sections $(5 \mu \mathrm{m})$ were dewaxed in histoclear, rinsed in three changes of ethanol, rehydrated in descending concentrations of ethanol and rinsed in distilled water. Antigen retrieval was performed by boiling the slides for $10 \mathrm{~min}$ in citrate buffer $(0.01 \mathrm{M}$ sodium citrate, $0.5 \%$ Tween 20 and $\mathrm{pH}$ 6.0) in a microwave oven, followed by $30 \mathrm{~min}$ cool down and 10 min wash in distilled water. For double staining, the sections were blocked in 10\% normal goat serum or $10 \%$ normal donkey serum (for all POU5F1 staining) in PBS for $1 \mathrm{~h}$ and incubated with the primary antibodies/lectin for $1 \mathrm{~h}$ at room temperature or overnight at $4{ }^{\circ} \mathrm{C}$ in blocking solution. The CT1 antibody $(2 \mu \mathrm{g} / \mathrm{ml})$ was used in combination with one of the following: biotinylated DBA $(10 \mu \mathrm{g} / \mathrm{ml}$, Sigma), anti-POU5F1 ( $2 \mu \mathrm{g} / \mathrm{ml}$, Santa Cruz Biotechnology Santa Cruz, CA, USA) or anti-UCHL1 (rabbit antiserum, 1:1000, Enzo Life Science, Exeter, UK). Slides were washed twice for $5 \mathrm{~min}$ in PBS. The antibody/lectin binding was visualised by incubation with fluorochromelabelled secondary antibodies in 10\% blocking serum in PBS for $90 \mathrm{~min}$. CT1 was detected with FITC-labelled donkey anti-mouse $(0.5 \mu \mathrm{g} / \mathrm{ml}$, Vector Laboratories, Burlingame, CA, USA) and the biotinylated DBA with streptavidin-Cy3 $(0.25 \mu \mathrm{g} / \mathrm{ml}$, Invitrogen). A Cy3-labelled donkey anti-goat antibody ( $4 \mu \mathrm{g} / \mathrm{ml}$, Vector Laboratories) was used to visualise POU5F1 and an Alexa488-labelled goat anti-rabbit $(2 \mu \mathrm{g} / \mathrm{ml}$, Invitrogen) was used to visualise the UCHL1. Slides were washed three times for $10 \mathrm{~min}$ in PBS, counterstained with DAPI (1:10 000) and mounted in Vectashield (Vector Laboratories). In controls, the incubation was carried out under identical conditions, but without the primary reagents (CT1, POU5F1, UCHL1 antibodies or DBA).

\section{Supplementary data}

This is linked to the online version of the paper at http://dx.doi. org/10.1530/REP-11-0007.

\section{Declaration of interest}

The authors declare that there is no conflict of interest that could be perceived as prejudicing the impartiality of the research reported.

\section{Funding}

D A Contreras was funded by a scholarship from CONACYT Mexico.

\section{Acknowledgements}

We would like to thank Ceri Allen for technical support and the Consortium for Functional Glycomics, funded by NIGMS GM62116, for the glycan array resources and collaborative efforts. The CT1-hybridoma was a gift from L Lefrancois, University of Connecticut, Farmington, CT, USA.

\section{References}

Abd-Elmaksoud A 2005 Morphological, glycohistochemical, and immunohistochemical studies on the embryonic and adult bovine testis. PhD Thesis. LMU München: Faculty of Veterinary Medicine.

Anglin E, Davey R, Herrid M, Hope S, Kurkuri M, Pasic P, Hor M, Fenech M, Thissen H \& Voelcker NH 2010 Cell microarrays for the screening of factors that allow the enrichment of bovine testicular cells. Cytometry. Part A 77 881-889. (doi:10.1002/cyto.a.20913)

Aponte PM, Soda T, Teerds KJ, Mizrak SC, van de Kant HJ \& de Rooij DG 2008 Propagation of bovine spermatogonial stem cells in vitro. Reproduction 136 543-557. (doi:10.1530/REP-07-0419)

Brinster RL \& Zimmermann JW 1994 Spermatogenesis following male germ-cell transplantation. PNAS 91 11298-11302. (doi:10.1073/pnas. 91.24.11298)

Debarbieux S, Popa I, Thomas L, Kanitakis J, Pirot F, Portoukalian J \& Haftek M 2009 Detection of GD3 ganglioside in primary melanomas depends on histopathologic procedures used for tumor preservation. Acta Dermatovenerologica Croatica 17 209-216.

Dym M, He Z, Jiang J, Pant D \& Kokkinaki M 2009 Spermatogonial stem cells: unlimited potential. Reproduction, Fertility, and Development $\mathbf{2 1}$ 15-21. (doi:10.1071/RD08221)

Easton RL, Patankar MS, Clark GF, Morris HR \& Dell A 2000a Pregnancyassociated changes in the glycosylation of Tamm-Horsfall glycoprotein. Expression of sialyl Lewis(x) sequences on core 2 type $O$-glycans derived from uromodulin. Journal of Biological Chemistry 275 21928-21938. (doi:10.1074/jbc.M001534200)

Easton RL, Patankar MS, Lattanzio FA, Leaven TH, Morris HR, Clark GF \& Dell A $2000 b$ Structural analysis of murine zona pellucida glycans. Evidence for the expression of core 2-type O-glycans and the $\mathrm{Sd}(\mathrm{a})$ antigen. Journal of Biological Chemistry 275 7731-7742. (doi:10.1074/ jbc.275.11.7731)

Ertl C \& Wrobel KH 1992 Distribution of sugar residues in the bovine testis during postnatal ontogenesis demonstrated with lectin-horseradish peroxidase conjugates. Histochemistry 97 161-171. (doi:10.1007/ BF00267307)

Fujihara M, Kim SM, Minami N, Yamada M \& Imai H 2011 Characterization and in vitro culture of male germ cells from developing bovine testis. Journal of Reproduction and Development 57 355-364. (doi:10.1262/ jrd.10-185M)

Goel S, Sugimoto M, Minami N, Yamada M, Kume S \& Imai H 2007 Identification, isolation, and in vitro culture of porcine gonocytes. Biology of Reproduction 77 127-137. (doi:10.1095/biolreprod.106. 056879)

Ha TY, Ahn MJ, Lee YD, Yang JH, Kim HS \& Shin TK 2003 Histochemical detection of glycoconjugates in the male reproductive system of the horse. Journal of Veterinary Science 4 21-28. 
Harris PL \& Thornton ER 1978 C-13 and proton nuclear magneticresonance studies of Gangliosides. Journal of the American Chemical Society 100 6738-6745. (doi:10.1021/ja00489a032)

Herrid M, Davey RJ \& Hill JR 2007 Characterization of germ cells from pre-pubertal bull calves in preparation for germ cell transplantation. Cell Tissue Research 330 321-329. (doi:10.1007/s00441-007-0445-z)

Herrid M, Davey RJ, Hutton K, Colditz IG \& Hill JR 2009 A comparison of methods for preparing enriched populations of bovine spermatogonia. Reproduction, Fertility, and Development 21 393-399. (doi:10.1071/ RD08129)

Hill JR \& Dobrinski I 2006 Male germ cell transplantation in livestock. Reproduction, Fertility, and Development 18 13-18. (doi:10.1071/ RD05123)

Hyldig SM, Croxall N, Contreras DA, Thomsen PD \& Alberio R 2011 Epigenetic reprogramming in the porcine germ line. BMC Developmental Biology 11 11. (doi:10.1186/1471-213X-11-11)

Izadyar F, Spierenberg GT, Creemers LB, den Ouden K \& de Rooij DG 2002 Isolation and purification of type A spermatogonia from the bovine testis. Reproduction 124 85-94. (doi:10.1530/rep.0.1240085)

Kamada Y, Muramatsu H, Arita Y, Yamada T \& Muramatsu T 1991 Structural studies on a binding site for Dolichos biflorus agglutinin in the small intestine of the mouse. Journal of Biochemistry 109 178-183.

Kim BG, Cho CM, Lee YA, Kim BJ, Kim KJ, Kim YH, Min KS, Kim CG \& Ryu BY 2010 Enrichment of testicular gonocytes and genetic modification using lentiviral transduction in pigs. Biology of Reproduction $\mathbf{8 2}$ 1162-1169. (doi:10.1095/biolreprod.109.079558)

Klisch K, Jeanrond E, Pang PC, Pich A, Schuler G, Dantzer V, Kowalewski MP \& Dell A 2008 A tetraantennary glycan with bisecting $\mathrm{N}$-acetylglucosamine and the $\mathrm{Sd}(\mathrm{a})$ antigen is the predominant $\mathrm{N}$-glycan on bovine pregnancy-associated glycoproteins. Glycobiology 18 42-52. (doi:10.1093/glycob/cwm113)

Ko K, Tapia N, Wu G, Kim JB, Bravo MJ, Sasse P, Glaser T, Ruau D, Han DW, Greber B et al. 2009 Induction of pluripotency in adult unipotent germline stem cells. Cell Stem Cell 5 87-96. (doi:10.1016/j.stem.2009. 05.025)

Kossack N, Meneses J, Shefi S, Nguyen HN, Chavez S, Nicholas C, Gromoll J, Turek PJ \& Reijo-Pera RA 2009 Isolation and characterization of pluripotent human spermatogonial stem cell-derived cells. Stem Cells 27 138-149. (doi:10.1634/stemcells.2008-0439)
Lefrancois L \& Bevan MJ 1985 Functional modifications of cytotoxic T-lymphocyte T200 glycoprotein recognized by monoclonal antibodies. Nature 314 449-452. (doi:10.1038/314449a0)

Piller V, Piller F \& Cartron JP 1990 Comparison of the carbohydrate-binding specificities of seven $\mathrm{N}$-acetyl-D-galactosamine-recognizing lectins. European Journal of Biochemistry 191 461-466. (doi:10.1111/j.14321033.1990.tb19144.x)

Pinart E, Bonet S, Briz M, Pastor LM, Sancho S, Garcia N, Badia E \& Bassols J 2001 Lectin affinity of the seminiferous epithelium in healthy and cryptorchid post-pubertal boars. International Journal of Andrology 24 153-164. (doi:10.1046/j.1365-2605.2001.00282.x)

Serafini-Cessi F, Monti A \& Cavallone D 2005 N-Glycans carried by TammHorsfall glycoprotein have a crucial role in the defense against urinary tract diseases. Glycoconjugate Journal 22 383-394. (doi:10.1007/ s10719-005-2142-z)

Takagi Y, Talbot NC, Rexroad CE Jr \& Pursel VG 1997 Identification of pig primordial germ cells by immunocytochemistry and lectin binding. Molecular Reproduction and Development 46 567-580. (doi:10.1002/ (SICI)1098-2795(199704)46:4 < 567::AID-MRD14>3.0.CO;2-T)

Verini-Supplizi A, Stradaioli G, Fagioli O \& Parillo F 2000 Localization of the lectin reactive sites in adult and prepubertal horse testes. Research in Veterinary Science 69 113-118. (doi:10.1053/rvsc.2000.0398)

Wrobel KH \& Suss F 1998 Identification and temporospatial distribution of bovine primordial germ cells prior to gonadal sexual differentiation. Anatomy and Embryology 197 451-467. (doi:10.1007/ s004290050156)

Wu AM, Wu JH, Watkins WM, Chen CP, Song SC \& Chen YY 1998 Differential binding of human blood group $\mathrm{Sd}(\mathrm{a}+)$ and $\mathrm{Sd}(\mathrm{a}-)$ TammHorsfall glycoproteins with Dolichos biflorus and Vicia villosa-B4 agglutinins. FEBS Letters 429 323-326. (doi:10.1016/S0014-5793(98) 00617-6)

Received 10 January 2011

First decision 9 February 2011

Revised manuscript received 16 August 2011

Accepted 6 September 2011 